\title{
Patient fibroblast circadian rhythms predict lithium sensitivity in bipolar disorder
}

\author{
Harshmeena R. Sanghani ${ }^{1}$ - Aarti Jagannath $\mathbb{1}^{2} \cdot$ Thomas Humberstone $^{1} \cdot$ Farid Ebrahimjee $^{1}$ - Justyn M. Thomas ${ }^{3}$. \\ Grant C. Churchill ${ }^{1}$ - Andrea Cipriani $\mathbb{D}^{4,5}$ - Mary-Jane Attenburrow ${ }^{4,5}$ - Olga V. Perestenko ${ }^{6}$ - Sally A. Cowley ${ }^{6}$. \\ M. Zameel Cader ${ }^{7}$. Stuart N. Peirson ${ }^{2} \cdot$ Paul J. Harrison $\mathbb{1 0}^{4,5} \cdot$ Russell G. Foster $^{2} \cdot$ Guy M. Goodwin $^{4}$. \\ Sridhar R. Vasudevan ${ }^{1}$
}

Received: 17 September 2018 / Revised: 27 April 2020 / Accepted: 29 April 2020 / Published online: 13 May 2020

(c) The Author(s) 2020. This article is published with open access

\begin{abstract}
Bipolar disorder is a chronic neuropsychiatric condition associated with mood instability, where patients present significant sleep and circadian rhythm abnormalities. Currently, the pathophysiology of bipolar disorder remains elusive, but treatment with lithium continues as the benchmark pharmacotherapy, functioning as a potent mood stabilizer in most, but not all patients. Lithium is well documented to induce period lengthening and amplitude enhancement of the circadian clock. Based on this, we sought to investigate whether lithium differentially impacts circadian rhythms in bipolar patient cell lines and crucially if lithium's effect on the clock is fundamental to its mood-stabilizing effects. We analyzed the circadian rhythms of bipolar patient-derived fibroblasts $(n=39)$ and their responses to lithium and three further chronomodulators. Here we show, relative to controls $(n=23)$, patients exhibited a wider distribution of circadian period $(p<0.05)$, and that patients with longer periods were medicated with a wider range of drugs, suggesting lower effectiveness of lithium. In agreement, patient fibroblasts with longer periods displayed muted circadian responses to lithium as well as to other chronomodulators that phenocopy lithium. These results show that lithium differentially impacts the circadian system in a patient-specific manner and its effect is dependent on the patient's circadian phenotype. We also found that lithium-induced behavioral changes in mice were phenocopied by modulation of the circadian system with drugs that target the clock, and that a dysfunctional clock ablates this response. Thus, chronomodulatory compounds offer a promising route to a novel treatment paradigm. These findings, upon larger-scale validation, could facilitate the implementation of a personalized approach for mood stabilization.
\end{abstract}

Supplementary information The online version of this article (https:// doi.org/10.1038/s41380-020-0769-6) contains supplementary material, which is available to authorized users.

Aarti Jagannath

aarti.jagannath@nden.ox.ac.uk

$\triangle$ Sridhar R. Vasudevan

Sridhar.vasudevan@pharm.ox.ac.uk

1 Department of Pharmacology, University of Oxford, Mansfield Road, Oxford OX1 3QT, UK

2 Nuffield Department of Clinical Neurosciences, University of Oxford, OMPI-G, South Parks Road, Oxford OX1 3RE, UK

3 Addenbrookes Hospital, Cambridge University Hospitals NHS

\section{Introduction}

Bipolar disorder (BD) is a chronic illness characterized by recurrent episodes of abnormal mood. It affects $1-3 \%$ of the population worldwide and is one of the major causes of chronic disability $[1,2]$. The first-line treatment is lithium,

Foundation Trust, Cambridge CB2 0QH, UK

4 Department of Psychiatry, Warneford Hospital, University of Oxford, Oxford OX3 7JX, UK

5 Oxford Health NHS Foundation Trust, Warneford Hospital, Oxford OX3 7JX, UK

6 Sir William Dunn School of Pathology, University of Oxford, South Parks Road, Oxford OX1 3RE, UK

7 Weatherall Institute of Molecular Medicine, University of Oxford, Oxford OX3 9DS, UK 
functioning as a potent mood stabilizer in most patients [3-5]. Little is known about the molecular pathways that cause BD, other than hypotheses that build on a range of targets of lithium [6]. As a consequence, BD has been difficult to model in vitro, thus hampering drug discovery. One leading hypothesis is that lithium modulates circadian gene expression, and thus the stabilization of sleep and circadian rhythms might offer novel treatment paradigms.

Sleep and circadian rhythm disruption have been noted in many neuropsychiatric disorders, including BD [7-9]. Virtually all aspects of mammalian physiology and behavior display $24 \mathrm{~h}$ circadian rhythms, driven by a series of transcriptional-translational feedback loops that yield cellautonomous rhythm generation. The core of this molecular clock is composed of CLOCK and BMAL1, which regulate the expression of their negative repressors Per (Period 1/2) 3 ) and Cry (Cryptochrome 1/2), thus forming a process that repeats every $24 \mathrm{~h} \mathrm{[10].} \mathrm{Indeed,} \mathrm{the} \mathrm{comorbid} \mathrm{nature} \mathrm{of}$ sleep/circadian disruption and mood is now well established [11-13]: Diagnostic and Statistical Manual of Mental Disorders 5 now recognizes this as a diagnostic criterion for manic and depressive episodes [14].

At the mechanistic level, genes such as Clock, Bmall, and $P e r$, which are intimately involved in the generation and regulation of circadian rhythms, have been linked to $\mathrm{BD}$ $[15,16]$, and this is supported by mouse models. Clock $\Delta 19$ mutant mice, for example, in addition to displaying sleep and circadian deficits (reduced sleep requirement and increased circadian period), display mania-like behaviors including reduced anxiety and depression-like behaviors, as well as increased risk taking and hyperhedonia [17, 18]. Consistent with the Clocks19 mutant, Afh (After-hours) mice which carry a mutation in the clock-gene $F b x l 3$ thereby preventing Cry (1/2) degradation, display significantly altered rhythms and a mania-like phenotype [19-21], further reinforcing a strong link between period length and moodrelated behaviors, and by extension BD and clock genes.

The highly accessible nature of skin cells and their ability to pass on circadian timing to daughter cells, make fibroblasts a valid and promising tool for assessing human circadian rhythmicity [22]. Previous use of healthy human or murine cells have found that the molecular clocks within fibroblasts provide an accurate indication of rhythms generated in vivo and by the SCN [23-25]. Previous clock-gene luminometric analysis found the period to be elongated by up to $25 \mathrm{~min}$ in BD patient cells [26]. A subsequent study found that BD fibroblasts exhibited nonsignificant (40 min) trends in period lengthening [27] (Table 1).

Alongside these circadian abnormalities in BD, several mood stabilizers, including lithium, have an effect on the clock [28-30]. Lithium has been shown to increase the amplitude and period of circadian rhythms in a range of
Table 1 Summary of previous fibroblast bioluminescence reporter studies assessing molecular rhythmicity from healthy controls or bipolar patients.

\begin{tabular}{lllll}
\hline Subject & $n$ & Gene & Period (h) & Publication \\
\hline Control & 19 & Bmall & $24.5 \pm 0.75$ (s.d.) & Brown et al. [23] \\
Control & 28 & Bmall & $24.5 \pm 0.75$ (s.e.m.) & Brown et al. [25] \\
& 9 & & $24.71 \pm 0.38$ (s.e.m.) & Pagani et al. [24] \\
Control & 11 & Bmall & $24.77 \pm 0.42$ (s.e.m.) & Pagani et al. [24] \\
& 8 & & $24.46 \pm 0.48$ (s.e.m.) & Pagani et al. [24] \\
Control & 19 & Per2 & $25.10 \pm 0.20$ (s.e.m.) & McCarthy et al. [26] \\
BD & 19 & & $25.50 \pm 0.20$ (s.e.m.) & McCarthy et al. [26] \\
Control & 12 & Bmall & $25.50 \pm 0.60$ (s.d.) & Bamne et al. [27] \\
BD & 13 & & $26.30 \pm 1.20$ (s.d.) & Bamne et al. [27] \\
\hline
\end{tabular}

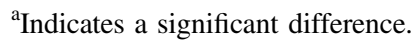

organisms from plants to humans [31-34]. As the targets of lithium are many and various downstream consequences remain unknown, the mechanism by which lithium acts on the circadian system may be an attractive target for mood modulation. Further, recent evidence of lithium's action on the clock comes from effects on BD patient lymphoblastic cell lines [35]. Two days after treatment, cells from lithiumresponsive patients (unlike those from nonresponsive patients) demonstrated elevated expression of the core clock components Bmall, Perl, and Cry2, providing further clinical insight into the effects of lithium.

Here we have analyzed the circadian rhythms and chronomodulatory drug responses of BD patient-derived fibroblasts. We sought to answer three questions: (1) does lithium differentially impact circadian rhythms in different patient cell lines; (2) is lithium's effect on the clock necessary for mood stabilization; and (3) what factors predispose individuals toward sensitivity to lithium. While lithium remains the first-line drug for $\mathrm{BD}$, clinical response varies. Accordingly, polypharmacy is common, and often therapeutically necessary. We hypothesized that patients taking fewer medications do so because their circadian clocks respond well to lithium treatment, whereas those that need a greater number of medications have a circadian clock that is less responsive to chronomodulation.

We found that BD patients exhibited a wide distribution of period length. Those with longer basal circadian periods took more medications overall and displayed attenuated responses to lithium (as well as alternative validated chronomodulators), implying that lithium differentially impacts the circadian system and that efficacy is determined by the patients underlying circadian phenotype. Furthermore, we show that drugs that phenocopy lithium's circadian response in patient fibroblasts elicit behavioral alterations akin to those for lithium in mice, and that a 
dysfunctional clock grossly alters murine lithium-induced behavioral responses, suggesting an intricate link between the circadian clock and lithium therapy.

\section{Patients and methods}

\section{Compounds and reagents}

All reagents were from Sigma-Aldrich except where stated otherwise. Nuclease-free water or sterile DMSO was used to prepare the compounds.

\section{Subject characteristics}

The control subjects who donated fibroblasts had an average age of $53.56 \pm 3.18$ years. The BD subjects had an average age of $43.10 \pm 1.97$ years; $82 \%$ were diagnosed with BP-I disorder, and $67 \%$ presented with psychotic symptoms. The patients were further divided into those who were lithiumtreated (Li-T) and lithium-non-treated (Li-NT); 77\% of the patients were taking lithium at the time of the biopsy (Table S1) for an average of 10 years (Table S2). Only 20\% of patients were on lithium alone. In the rest, an assortment of additional drugs (up to six) had been added to control mood instability. The drugs were divided into five classes by indication (Tables S3, S4). Patients were taking on average a combination of two or three compounds across multiple drug classes; mood stabilizers and antipsychotics were the medications most frequently reported.

\section{Cell lines}

BD patient-derived dermal fibroblasts $(n=39)$ and control subject-derived dermal fibroblasts $(n=23)$ were obtained from the StemBANCC consortia, who oversaw the collection and culturing of cells from 500 individuals under standardized conditions. Fibroblasts were derived from 3 $\mathrm{mm}$ punch-skin biopsies, following informed consent in accordance with StemBANCC ethics practice [36]. Biopsies were plated in Advanced DMEM (ADMEM, ThermoFisher Scientific, Waltham, Massachusetts, USA) with $10 \%$ Fetal Bovine Serum (FBS) for outgrowth of fibroblasts, with subsequent expansion for generating a banked frozen stock in $10 \%$ DMSO at passage 2 in nitrogen vapor. This was further expanded for functional studies, which were carried out at passages 4-6.

\section{Lentivirus production and cell-line generation}

Mass production of Bmall-Luc or Per2-Luc virus was performed to infect fibroblasts with the same batch of lentivirus. HEK-293 cells were seeded in HYPERflasks
(Corning, Corning, New York, USA). The plasmid complex included: $60.4 \mu \mathrm{g}$ reporter plasmid; Per2 (gift from QingJung Meng Lab) [37] and Bmall (pABpuro-BluF was a gift from Steven Brown (Addgene plasmid \# 46824)), $40.25 \mu \mathrm{g}$ packaging (psPAX2 was a gift from Didier Trono Addgene plasmid \# 12260), $16.1 \mu \mathrm{g}$ envelope plasmid (pMD2.G was a gift from Didier Trono (Addgene plasmid \# 12259), and $1 \mathrm{~mL}$ of PEI-25 kDa $(1 \mathrm{mg} / \mathrm{mL}$; Polyscience, Warrington, Pennsylvania, USA) as the transfection reagent. Then, $16 \mathrm{~h}$ post transfection, the cellular media (DMEM, SigmaAldrich, St. Louis, Missouri, USA) was replaced with fresh media and incubated at $37^{\circ} \mathrm{C}$ for $48 \mathrm{~h}$, as previously described [38]. The viral supernatant was concentrated in a Vivaspin 20 and quantified using a p24 ELISA (Takara Bio, Paris, France).

Fibroblasts grown in $75 \mathrm{~cm}^{2}$ flasks were transduced with a spinfection protocol. Briefly, 100,000 fibroblast cells to be transduced were lifted with TrypLE (ThermoScientific) and centrifuged with $200 \mu \mathrm{l}$ virus $(\sim \mathrm{MOI} 20)$ at $3000 \times g, 25^{\circ} \mathrm{C}$ for $99 \mathrm{~min}$. Cells were then resuspended in viral medium and incubated at $37^{\circ} \mathrm{C}$ overnight prior to use.

\section{Assessing circadian rhythms}

Fibroblasts were cultured to confluence $(\sim 30,000$ cells/ well) in 96-well white plates (Greiner Bio-One, Gloucestershire, UK) using ADMEM (ThermoScientific) containing $10 \%$ FBS and $1 \%$ penicillin-streptomycin. Cells were synchronized with $200 \mathrm{nM}$ dexamethasone, diluted in serum-free medium for an hour and washed twice with the same solution (ThermoScientific) before reconstituting with serum-free medium containing $1 \times$ B27 (ThermoScientific) and $400 \mu \mathrm{M}$ luciferin (Gold Biotechnology, St. Louis, Missouri, USA). Bioluminescence was recorded for 4 days in Tecan M200 Pro readers. Actimetrics MultiCycle was used to determine the period and amplitude (baseline subtracted $24 \mathrm{~h}$ running average of the raw luminescence data smoothed over $8 \mathrm{~h}$ ). For luminometric experiments involving the 62 fibroblast cell lines, three technical replicates per dose, per drug, were conducted once and averaged.

\section{Correlograms}

The statistical program $\mathrm{R}$ generated correlograms which portray the correlation coefficient using a Pearson's parametric correlation test from +1 to -1 in Fig. 1f. Blue and red are indicative of a positive and negative correlation respectively; a larger circle represents stronger correlation. Significance was assessed using a two-tailed $t$ test (bottom left); top right indicates significance following adjustments for multiple comparisons using the Holm-Bonferroni test. 
A

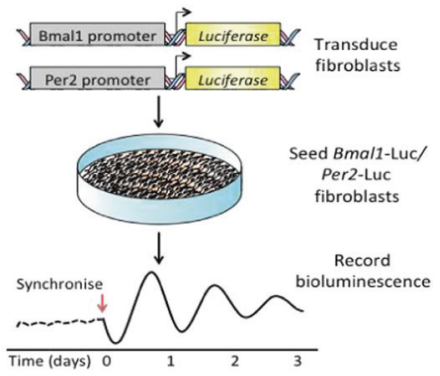

D

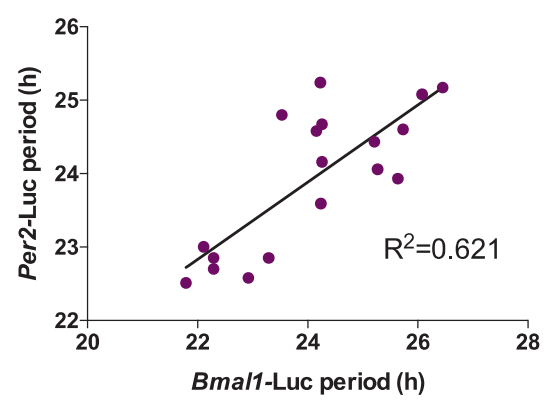

E

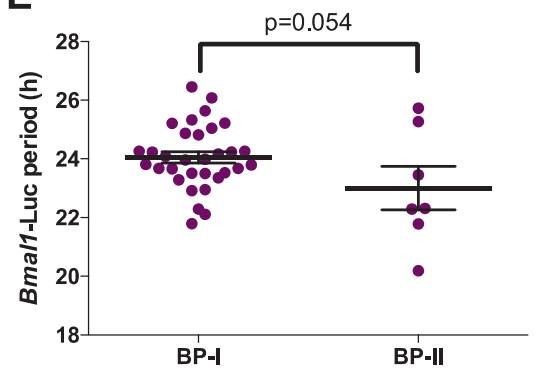

Fig. 1 Lentivirus-transduced BP patient fibroblasts express a variable underlying circadian phenotype. a Protocol to assess circadian rhythmicity. b Bmall-Luc period differences between control $(n=23)$ or BD patient $(n=39)$ fibroblasts were analyzed using twotailed Student's $t$ test with Welch's correction, enabling variance analysis. c Example oscillations from control and BD cells transduced with the Bmal1-Luc lentivirus. d Linear regression comparing Bmal1Luc rhythms with Per2-Luc rhythms in BD patient-derived fibroblasts

\section{Animals}

Wild-type male C57BL/6J (Envigo, Huntingdon, UK) and male Cryl/2 ${ }^{-/-}$mice (a kind gift from Patrick Nolan, MRC, Harwell, UK) of 8-12 weeks of age were housed under 12 $\mathrm{h}: 12 \mathrm{~h}$ LD cycles for 1 week. The $C r y 1 / 2^{-/-}$mice [39] were maintained as a homozygous line in the C57BL/6J background with regular backcrossing. Animals were housed and assessed in a randomized manner across treatment groups to avoid effects associated with housing location or order of treatments. All analyses were automated to remove user involvement. Each experiment involving a particular treatment group/genotype was performed on a cohort of the indicated size on a single occasion. Sample sizes were
C
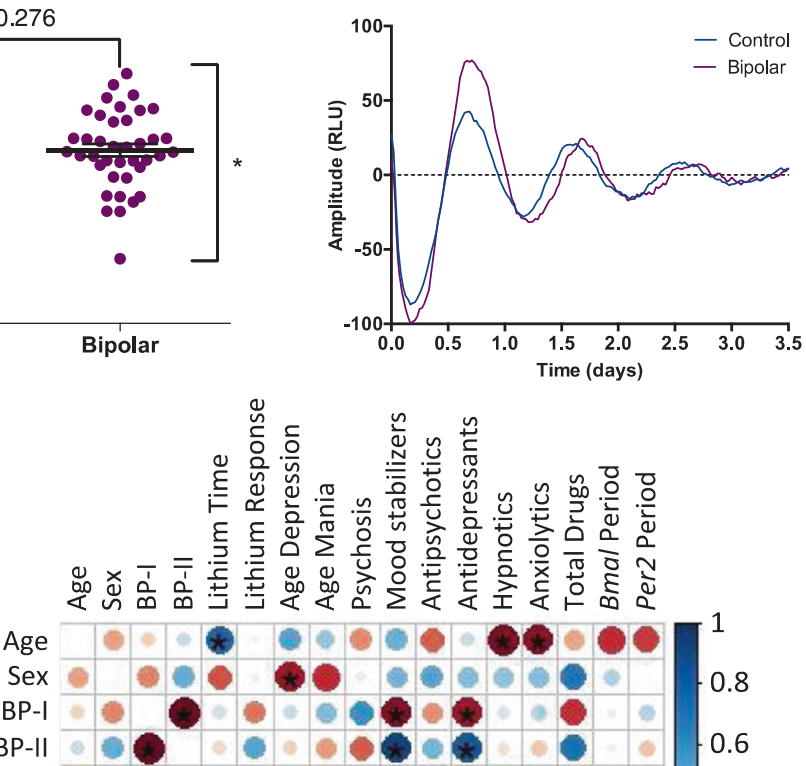

BP-II
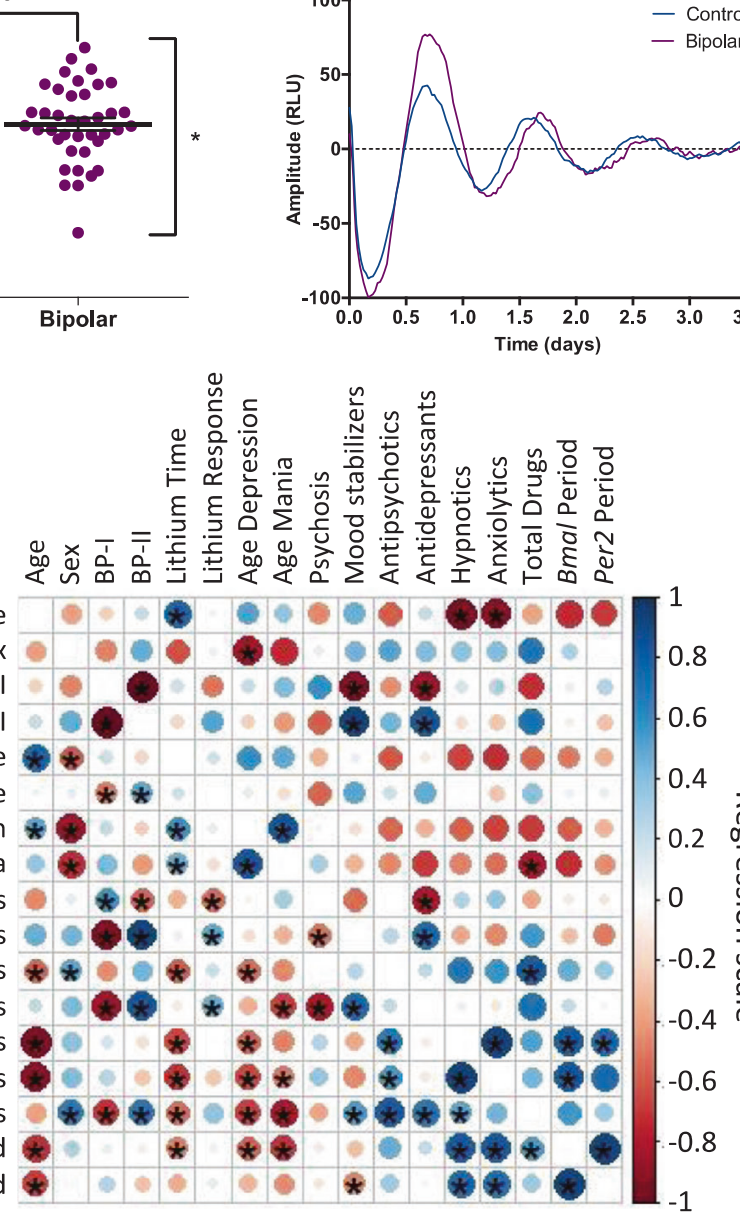

$(n=18)$ reveals a correlation $\left(R^{2}=0.621\right)$. e Comparison between BPI and BP-II cellular rhythms. f Correlogram revealing correlative patterns and their significance using a Pearson parametric correlation test on a scale of +1 to -1 . Blue indicates positive correlation; red for negative correlation; larger circles represent stronger correlation. Results from a Student's $t$ test are presented in the bottom left triangle, where the top right indicates significance following the Holm-Bonferroni test. Data are mean \pm s.e.m. $* p<0.05$.

estimated based on evidence from publications and past experiments within our laboratory. Wild-type mice were injected intraperitoneally (i.p.) with either vehicle $(n=7)$, $200 \mathrm{mg} / \mathrm{kg} \mathrm{LiCl}(n=6), 50 \mathrm{mg} / \mathrm{kg}$ nobiletin (NOB) $(n=7)$, or $5 \mathrm{mg} / \mathrm{kg}$ CGS-15943 (CGS) $(n=7)$. An independent experiment assessing the impact of $200 \mathrm{mg} / \mathrm{kg} \mathrm{LiCl}$ on Cryl $12^{-/-}$mice was also conducted (vehicle ${ }^{+/+}: n=6$, $\mathrm{LiCl}^{+/+}: n=7$, vehicle $\left.{ }^{\text {Cryl } / 2-l-}: n=8, \mathrm{LiCl}^{C r y l / 2-1-}: n=8\right)$. One mouse from the wild-type $\mathrm{LiCl}$ group and one mouse from the vehicle group were excluded due to in-cage fighting. The drugs were diluted in $0.9 \% \mathrm{NaCl}$ with $5 \%$ kolliphor HS 15 and 5\% 2-hydroxypropyl- $\beta$-cyclodextrin, except for $\mathrm{LiCl}$, which was diluted in $0.9 \% \mathrm{NaCl}$. Compounds were administered for $10-12$ days. The lithium dosage $(200 \mathrm{mg} / \mathrm{kg})$ was 
chosen based on previous studies [40]. All procedures were performed in accordance with the UK Home Office Animals (Scientific Procedures) Act 1986 and the University of Oxford's and NC3R's policy on the Use of Animals in Scientific Research.

\section{Open field test}

The open field test (OFT) was performed using the Linton AM1053 X, Y, Z IR Activity Monitor (San Diego Instruments, San Diego, California, USA). Animals were assessed in clear Perspex cages $(36 \times 20 \times 15 \mathrm{~cm})$ consisting of two parallel frames of 24 equally spaced beams along the $X$ and $Y(8 \times 16)$ axis. Animal activity was scored in $1 \mathrm{~min}$ time bins for $20 \mathrm{~min}$.

\section{Elevated plus maze}

The elevated plus maze (EPM) utilized a maze elevated 47 $\mathrm{cm}$ off the ground. The apparatus consisted of a central platform $(5 \times 5 \mathrm{~cm})$ with two opposing open arms $(28 \times 5$ $\mathrm{cm})$ lit to 290 lux and two opposing close arms $(28 \times 5 \times 30$ $\mathrm{cm}, 50$ lux). Each mouse was placed on the central platform facing the closed arms and animal activity was recorded for $10 \mathrm{~min}$. Video analysis was performed using ANY-maze 5.3 (Stoelting Co., Wood Dale, Illinois, USA). Mice that fell or jumped off the EPM apparatus were excluded from further analysis as these experiments were performed without the user being present in the room.

\section{Forced swim (Porsolt) test}

The forced swim test (FST) was performed in a glass cylinder $(18 \mathrm{~cm}$ diameter, $27 \mathrm{~cm}$ height) filled with $3.5 \mathrm{~L}$ water $\left(24 \pm 1{ }^{\circ} \mathrm{C}\right)$, a depth at which the animal's tail is unable to touch the bottom of the apparatus. Each mouse was kept in the water for 6 min before being dried in a clean cage and returned to the home cage. The water was changed after each subject. Video analysis was performed using ANY-maze 5.3.

\section{Data analysis}

Statistical analysis was performed using GraphPad Prism; the results are presented as average \pm s.e.m. The threshold for significance was $p<0.05$. An unpaired two-tailed $t$ test or welches $t$ test was performed when comparing two parameters. A one-way ANOVA with a Tukey or Dunnett's post hoc test was used when comparing multiple parameters. A two-way ANOVA with a Tukey or Sidak's post hoc test was applied when two independent variables were present.

\section{Results}

\section{The underlying circadian phenotype in BD}

In order to perform luminometric recordings and analysis of circadian rhythms in vitro, fibroblasts from BD patients and controls were transduced with lentivirus where luciferase expression was driven by activity at the Bmall or Per2 promoter regions (Fig. 1a). Following the creation of stable cell lines, the fibroblasts were synchronized with $200 \mathrm{nM}$ dexamethasone, and basal period length was analyzed. Both BD and control cells exhibited a normally distributed period, but the BD cohort presented with a larger distribution and significantly greater variance, detected using the Welch's correction (control period: $21.69-25.64 \mathrm{~h}$; BD: 20.19-26.45 h; $p=0.039$ ) (Fig. 1b). We saw no difference in basal period in BD patients compared with the controls (control: $24.03 \pm 0.20$ h, BD: $23.87 \pm 0.21$ h) (Fig. 1b, c). To validate this observation, an additional study with Per2 gene expression was performed on a cellular subset (Fig. S1A, B), and similar observations were obtained (control: $23.48 \pm$ $0.27 \mathrm{~h}$, bipolar: $23.93 \pm 0.23 \mathrm{~h}$ ). Regression analysis to assess the correlation between Bmall and Per2 bioluminescence rhythms (Fig. 1d) yielded a positive correlation $\left(R^{2}=0.621\right)$; patients with longer Bmall molecular rhythms were more likely to display longer Per2 rhythms.

We explored whether known demographic characteristics were responsible for the period variability within our BD subject cell lines. BD and control cells displayed similar growth rates (Fig. S1C). Furthermore, sex, age, the presence of psychotic symptoms, and other key features analyzed presented with no significant basal differences (Fig. S1D-H). Interestingly, the emergent trend (Fig. 1e) suggested that patients diagnosed with bipolar II disorder (BP-II-who experience hypomania, and depression is more prominent) had a period that was on average $1.1 \mathrm{~h}$ shorter than those with bipolar I disorder (BP-I-mania is more prominent) (BP-I: $24.05 \pm 0.19$, BP-II: $23.00 \pm 0.74 \mathrm{~h}$; $p=0.054$ ) [14]. This was the only parameter that approached significance in accounting for the variability observed (Fig. 1b).

We next explored the emergent correlations between circadian rhythms and treatment regime for the BD data in the Per2 and Bmall regression analysis in Fig. 1d, f. We detected a relationship between periodicity and medication: patients with a shorter circadian period were taking more mood stabilizers. By contrast, patients with a longer period were taking more hypnotics and anxiolytics. Furthermore, the longer the circadian period, the greater the total number of medications. Thus, this offered preliminary support for our hypothesis that patients exhibiting longer basal periods are less responsive to chronomodulation by lithium. 
Patient stratification reveals circadian drug responses to be a determinant of basal circadian rhythms

Our regression analysis (Fig. 1f) highlighted that patients with longer periods were taking more medications. Hence, to test the hypothesis that patients with longer periods are less sensitive to lithium-induced chronomodulation, patients were divided into three categories (Fig. 2a, Fig. S2A) based on period length: short (up to $23.49 \mathrm{~h}$ ), medium $(23.50-24.99 \mathrm{~h})$, and long ( $25.00 \mathrm{~h}$ or more), where period difference between successive groups was on average $1.5 \mathrm{~h}$. Their responses to lithium were determined experimentally.

The drug responses from control (Fig. S2B, C) and BD cells assigned to these categories exhibited a clear spectrum of dose-dependent responses (Fig. 2b, Fig. S2D). Significant differences were evident between dose and basal circadian period: long cells displayed lower period lengthening responses over 10-30 $\mathrm{mM}$ relative to short and medium cells (Fig. 2c). Lithium was found to be incapable of increasing the period beyond $27 \mathrm{~h}$, regardless of the basal period. This attenuated period increase in patients with longer periods implies a plateau response in the case of lithium. Nevertheless, the altered lithium's dependence on the basal circadian period (even when not approaching $27 \mathrm{~h}$ ) suggests a defect in the mechanism underpinning the clock machinery. In contrast, amplitude enhancement was uniformly observed (Fig. 2d) across all patient subgroups and lithium concentrations (Fig. 2d), thus demonstrating clear differences in lithium's effects on period and amplitude. A differential effect of lithium-affecting one property of the clock without affecting the other has not been described. This provides compelling support for the notion that these two properties are controlled independently [34]. Thus, as hypothesized, differences in lithium-induced period lengthening are determined by the underlying circadian phenotype.

To determine whether these differential chronomodulatory responses are unique to lithium or a general circadian response of long-phenotype patients, two additional compounds were assessed: nobiletin (NOB), a polymethoxylated flavone [41] and CGS-15943 (CGS), a nonspecific adenosine antagonist [42]. These function via different primary targets and pathways, but show lithiumlike phenotypic effects on the clock.

NOB preferentially increased period in our short-period fibroblasts at $10-30 \mu \mathrm{M}$, by up to $1.5 \mathrm{~h}$ (Fig. 2e). All categories presented amplitude enhancement, much as for lithium. Whilst no effect for basal period was identified, the clear and identifiable trend was that of muted amplitude enhancement within long-period cell lines (Fig. 2f). Therefore, NOB displayed trends for reduced chronomodulatory effects in long-phenotype patient cells similar to lithium.
Unlike lithium, CGS induced period lengthening across all categories. Cells derived from patients within the short, medium, or long category displayed maximal period lengthening by up to $12.6,11.3$, and $10.9 \mathrm{~h}$ (Fig. 2g), consistent with the trend for long-phenotype displaying muted responses. This further demonstrates that the observed ceiling of lithium's period increasing effect $(\sim 27 \mathrm{~h})$ is specific for lithium (Fig. 2c) rather than a category-wide phenomenon, as seen with CGS (Fig. 2g-h).

Collectively, built on these observations we hypothesized that the lack of lithium's effect in long-period cells was due to an inherent fault in the circadian network rather than a ceiling effect. Therefore a drug capable of shortening circadian period should demonstrate a similar divergent effect across patient groups. Indeed, this proved to be the case with 6-bromoindirubin-3'-oxime (BIO), a GSK $\beta$ inhibitor that has previously been shown to shorten circadian period (Fig. S2E, F) [34]. In a dose-response study conducted with BIO, the short-period cells responded as predicted, with period shortening. In contrast the long-period cells failed to demonstrate any shortening, in fact, they responded with a mild period increase. Thus, along with lithium, NOB, CGS, and BIO induced differential chronomodulatory responses conditional upon basal circadian rhythms.

\section{Fibroblasts' lithium responses do not discriminate between lithium-treated and non-treated patients}

As our BD subject-derived cells were shown to display patient-specific chronomodulatory responses to lithium, we were curious to understand whether cells from lithium nonmedicated (Li-NT) patients would display any aberrant pharmacological responses. Basal circadian period showed no significant differences between the groups (Fig. 3a). However, patients not taking lithium are not lithium non responders, as patients can decline lithium for other reasons (e.g., side effects, preference, or disbelief in the diagnosis). Li-T and Li-NT cells displayed comparable period lengthening in response to lithium (Fig. 3b); both groups contained patients from the short, medium, and long categories. Similarly, Li-T and Li-NT cells exhibited non-differential dose-dependent amplitude enhancement (2.4-fold and 2.7fold, respectively) with $30 \mathrm{mM} \mathrm{LiCl}$ (Fig. 3c).

\section{Nobiletin and CGS-15943 induce lithium-like behavioral changes in rodents}

Both NOB and CGS displayed lithium-like chronomodulatory changes dependent on the underlying basal period (Fig. 2e-h). Importantly, the three compounds exert their effects on the clock through different targets. We therefore decided to assess whether these compounds 

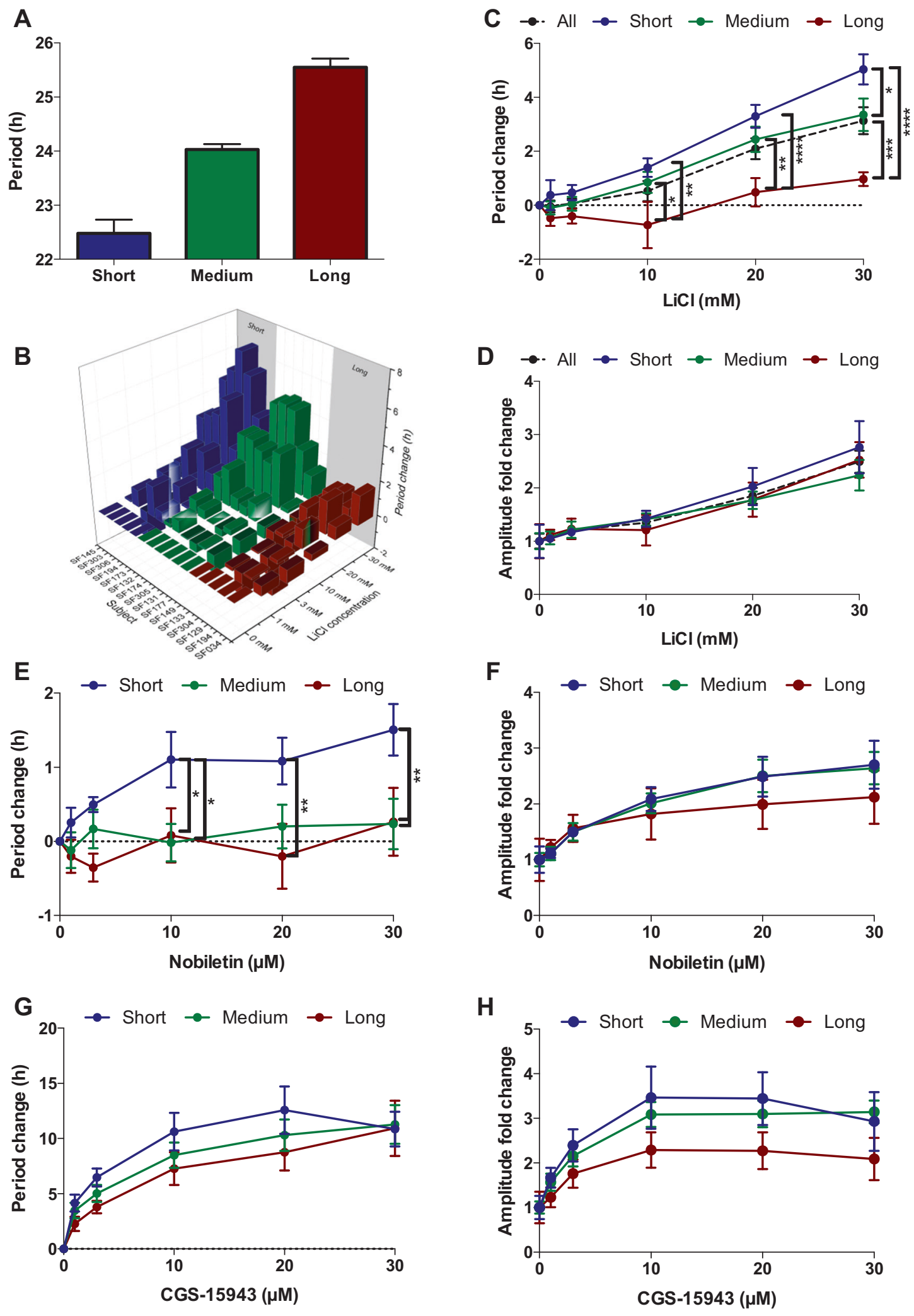

induce similar behavioral modifications. If true, this would suggest that pharmacological modulation of circadian rhythm directly modulates affective behaviors, thus

providing the basis for a novel treatment paradigm. To this end, we monitored two well-validated lithium-specific behavioral changes [43]. Following acclimatization, 
Fig. 2 The underlying patient-derived cellular circadian phenotype determines patient chronomodulatory responses to lithium, nobiletin, and CGS-15943. a Patients were divided into groups based on their basal Bmall-Luc period length: short ( $23.49 \mathrm{~h}$ or less, $n=13)$, medium (23.50-24.99 h, $n=17)$, and long ( $25.00 \mathrm{~h}$ or more, $n=9)$. b $3 \mathrm{D}$ plot displaying the variable dose-dependent period change induced by $\mathrm{LiCl}$ in 16 different $\mathrm{BD}$ patient cell lines. c Period and d amplitude effects induced by $1-30 \mathrm{mM} \mathrm{LiCl}$ in short $(n=5)$, medium $(n=6)$, or long $(n=5)$ BD fibroblasts. e, f Period and amplitude changes induced by NOB in short $(n=5)$, medium $(n=6)$, or long $(n=5)$ cells. $\mathbf{g}, \mathbf{h}$ Chronomodulatory changes induced by CGS in short $(n=5)$, medium $(n=6)$, or long $(n=5)$ fibroblasts. $\mathbf{c}-\mathbf{h}$ Data analysis was performed using a two-way ANOVA with a Tukey's post hoc test. Data are mean \pm s.e.m. $* p<0.05 ; * * p<0.01 ; * * * p<0.001$; $* * * * p<0.0001$

wild-type $\mathrm{C} 57 \mathrm{BL} / 6 \mathrm{~J}$ mice were administered i.p. injections of $\mathrm{LiCl}, \mathrm{NOB}$, or CGS. After the final dose on day 12, behavior was assessed using the OFT and EPM behavioral methods (Fig. 4a).

Rearing activity was monitored using the OFT. Lithium is well characterized to reduce rearing, an action indicative of exploration and impulsivity [43]. We found that lithium and NOB reduced the time spent rearing by 55 and $65 \%$ respectively; nonsignificant $(27 \%)$ reductions were observed with CGS (Fig. 4b, c). In addition, mice treated with lithium, NOB, and CGS reduced the number of central rearing episodes by $75 \%, 63 \%$, and $42 \%$ respectively (Fig. 4d, e). The overall activity of animals confirmed that our findings were not due to increased movement (Fig. 4f, g). Therefore, it was concluded that NOB and CGS show strong indications of lithium-like rearing behavior.

As lithium also modulates anxiety-related behaviors, we tested behavioral responses on the EPM [43]. Mice treated with $\mathrm{LiCl}$, NOB, or CGS were more likely to enter the open arms (2.7-, 2.5-, and 2.7-fold respectively; Fig. 4h), confirming that all three compounds possess anxiolytic-like effects. Furthermore, mice treated with $\mathrm{LiCl}$ spent 4.5-fold more time within the open arms; similarly, administering NOB or CGS increased the time in the open arms by 3.7and 3.9-fold, respectively (Fig. 4i). Much like our findings with the OFT, these compounds did not affect the amount of time spent active (Fig. 4j). Therefore, as exemplified by the tracking plots (Fig. 4k), NOB, and CGS phenocopied lithium-induced behavioral modification.

\section{Cry $1 / 2^{-/-}$mice display atypical behavioral changes with lithium treatment}

To understand whether a dysfunctional clock is detrimental for lithium treatment, we performed behavioral tests using Cry $1 / 2^{-/-}$mice. These mice have known circadian deficits, including arrhythmicity, and reduced circadian amplitude under constant conditions [44]. Thus, if the molecular clock plays a part in mediating lithium's effect, these should be

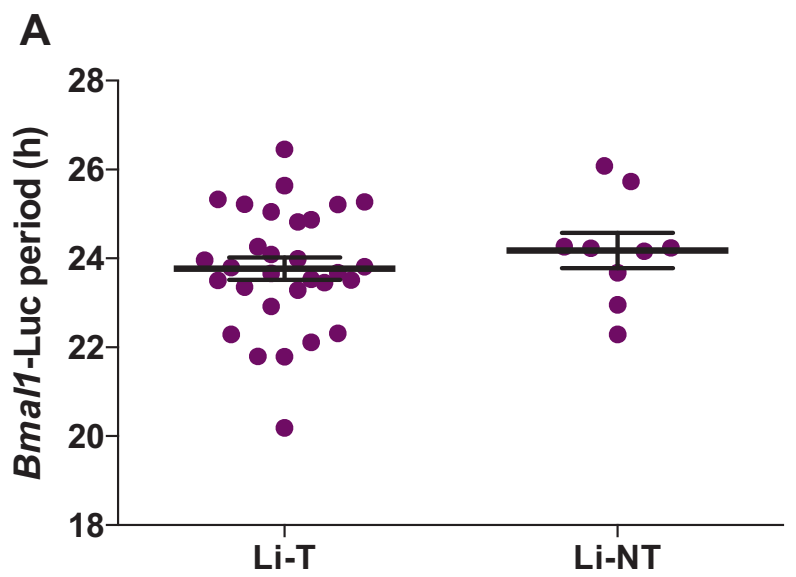

\section{Lithium treatment}
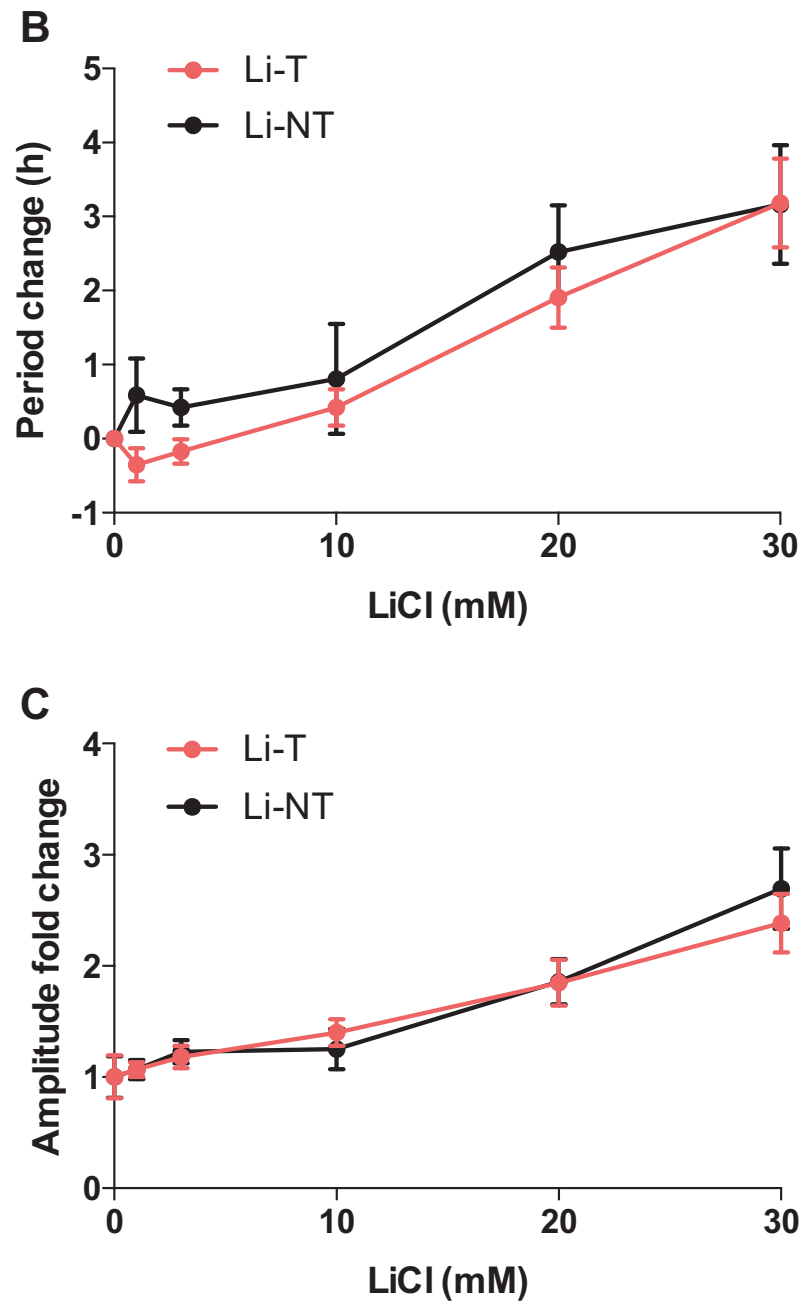

Fig. 3 Fibroblast lithium response do not discriminate between lithium-treated and non-treated patients. a BD patients divided according to lithium treatment; basal period differences analyzed using a two-tailed Student's $t$ test. b Period and $\mathbf{c}$ amplitude effects induced by $\mathrm{LiCl}$ in fibroblasts from Li-T $(n=10)$ and Li-NT patients $(n=6)$, analyzed using a two-way ANOVA with a Sidak's post hoc test. Data are presented as mean \pm s.e.m. 
A

repeated i.p. injections

(11 days)

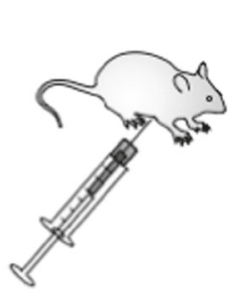

B

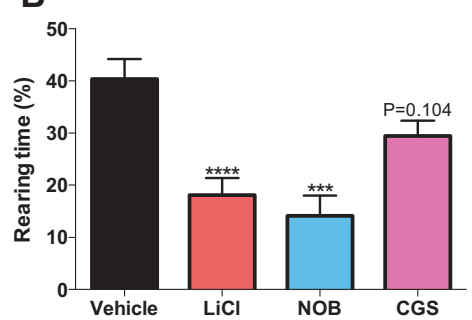

C

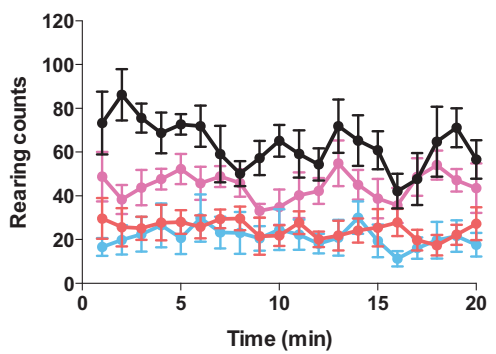

$\mathbf{H}$

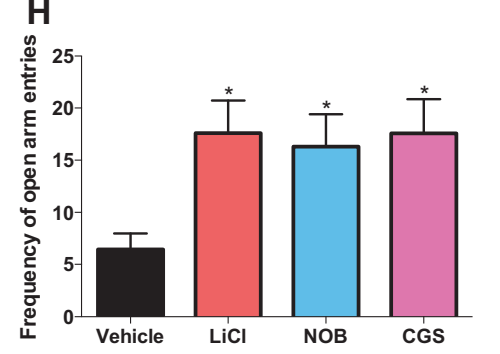

open field test
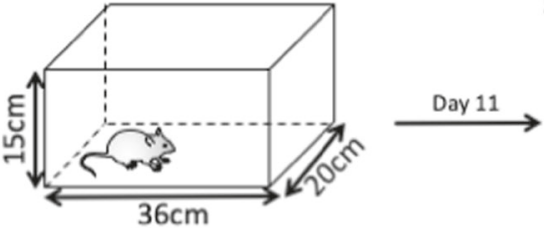

D

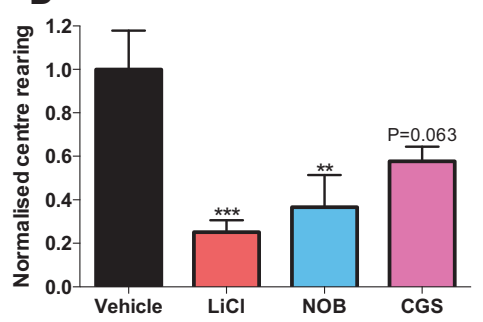

E

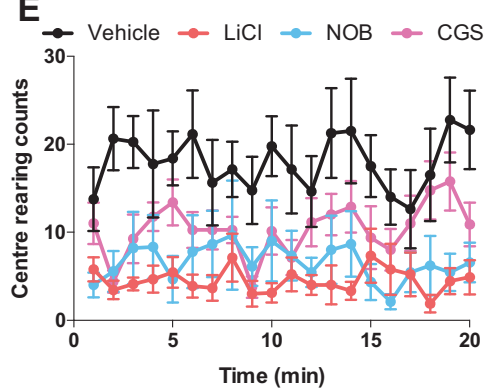

I

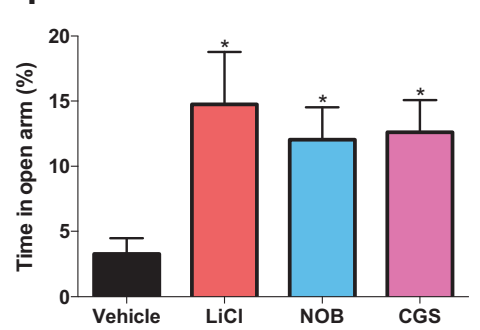

elevated plus maze
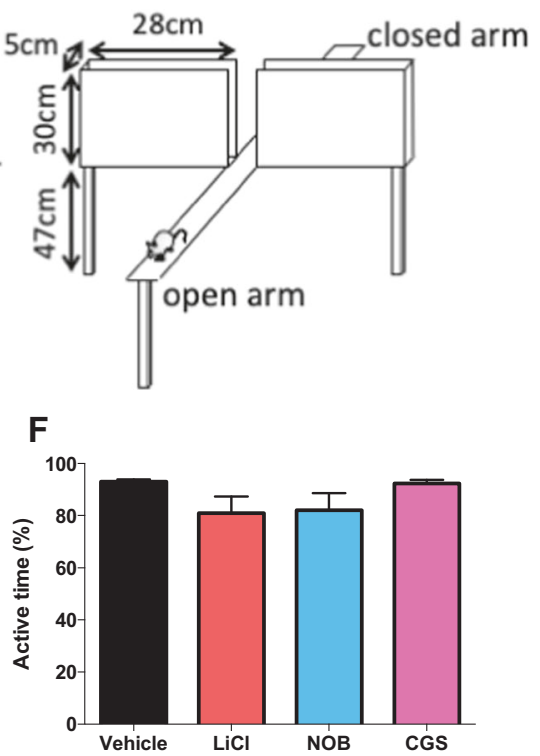

G

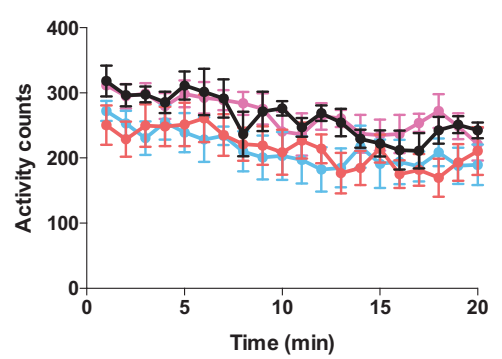

J

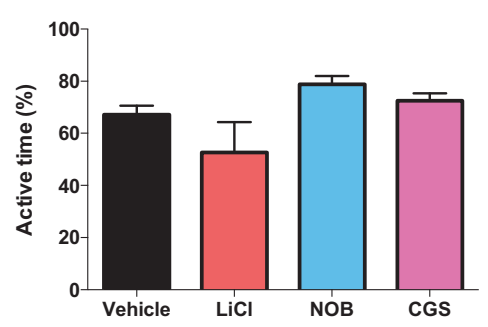

K

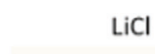

NOB CGS
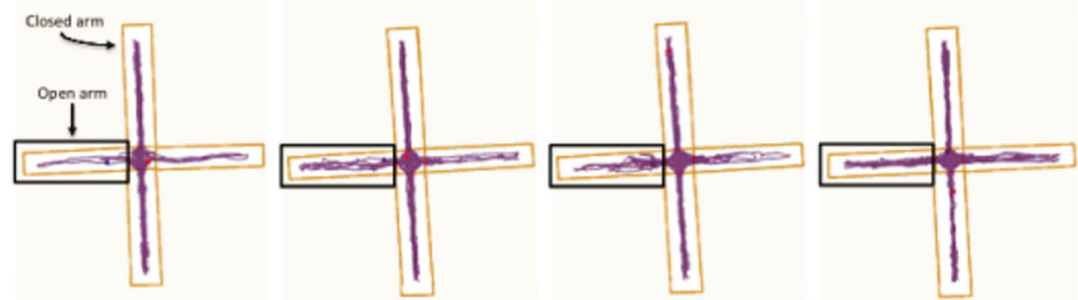

altered in the $\mathrm{Cry} 1 / 2^{-/-}$mice. Following i.p. injections of $\mathrm{LiCl}$, behavior was evaluated using the OFT, EPM, and FST (Fig. 5a).
There were no overall OFT differences in the in active time between lithium- and vehicle-treated animals (Fig. 5b, c). As expected, lithium reduced central rearing behavior in 
Fig. 4 Nobiletin and CGS-15943 as pharmacological modulators of circadian rhythms mimic behavioral changes induced by lithium. a C57BL/6J mice were administered (i.p.) vehicle $(n=7), \mathrm{LiCl}(n=$ $6)$, NOB $(n=7)$, or CGS $(n=7)$ then subjected to OFT and EPM behavioral tests. OFT: effects of compounds on $(\mathbf{b}, \mathbf{c})$ time spent rearing, (d, e) normalized number of center rears with representative traces, and (f, g) time spent active. EPM (1.5-2 h after the OFT): effects of compounds on (h) number of entries into the open arm, (i) time spent in the open arm, and (j) time spent active. k Representative tracking plots. Blue and red dots indicate mice positions when analysis began and ended, respectively. Data were analyzed using a one-way ANOVA with a Dunnett's post hoc test and are presented as mean \pm s.e.m. $* p<0.05 ; * * p<0.01 ; * * * p<0.001 ; * * * * p<0.0001$.

wild-type mice by $65 \%$; this was muted in Cry $1 / 2^{-/-}$mice along with total time spent rearing (Fig. 5d, e, Fig. S3A, B). In the FST behavioral test (also known as a despair test), lithium is known to increase the amount of time the animal is active [43]. Wild-type mice treated with lithium displayed a $34 \%$ reduction in immobility, whereas no significant differences were observed for Cry $1 / 2^{-/-}$mice (Fig. 5f, g; Fig. S3C). In the EPM test, nonsignificant divergent trends for increased frequency of open-arm entry and time spent in the open arms were observed between these groups (Fig. 5h, i, Fig. S3D). Importantly, lithium-altered behavioral response has also been demonstrated with Clock $\Delta 19$ mice [17]. Collectively, these data show that the typical lithiuminduced behavioral changes are significantly altered in mice with dysfunctional clocks.

\section{Discussion}

Here we show that patient fibroblasts exhibiting a longperiod circadian phenotype exhibit atypical chronomodulatory responses to lithium. Crucially, we found that this aberrant response extends to a range of chronomodulators that act via different molecular pathways, thus suggesting a fundamental defect in the clock pathways. Further, using circadian mutant mice we show that a functional clock is required to exhibit typical lithium-mediated behavioral responses. These data provide evidence to suggest that patients with a dysfunctional circadian clock may not exhibit typical clinical responses to lithium therapy. Importantly, we also show that drugs that phenocopy lithium at the cellular level elicit behavioral responses akin to lithium in mice. Taken together, the results strongly encourage the exploration of chronomodulation as a novel route to achieving mood stability, with the potential to translate into a new treatment paradigm for BD.

We could not confirm previous reports of longer circadian cycles in fibroblasts from patients with BD using two independent reporters. However, patients that exhibit a wider distribution of circadian period lengths and longer basal periods are associated with greater polypharmacy, indicating possible lower effectiveness of lithium in these patients. This is supported by the observation that longer basal circadian periods are associated with muted responses to chronomodulatory interventions with lithium. If lithium differentially impacts the circadian system and its efficacy is dependent on the patients' underlying circadian phenotype, this finding has important mechanistic and clinical implications. Pharmacological agents that modulated circadian rhythmicity in vitro also induced lithium-like behavioral changes in mice.

Using virally transduced Bmall-Luc and Per2-Luc subject-derived cells, we were unable to identify any significant differences in basal period length. This is in contrast to a previous study, which identified significant Per 2 period lengthening in BD by $25 \mathrm{~min}$ [26]. However, in accordance with our investigation, no significant effects have been observed with Bmall-Luc-transduced fibroblasts or mRNA analysis of patient cells [27, 45]. There are several reasons why we believe our data provide an accurate representation of the circadian state associated with BD. Firstly, the StemBANCC consortia rigorously selected patients to create a bio-bank for hard-to-treat disorders and thus fully phenotyped patients for subsequent studies. Secondly, the utilization of more patient cell lines ( $n=39$ in our study vs. $n=12-19$ in previous studies) may account for the wider spectrum of periods associated with BD. Finally, the lack of Bmall period lengthening in $\mathrm{BD}$ reported here is further strengthened by our observation showing a similar lack of period increase in BD using the Per2-reporter, further validating these findings. Whilst it would be useful to compare basal circadian amplitude between different patient cell lines due to previous reports of BD patients demonstrating muted amplitude, the number of viral integrations per fibroblast dictates the observed basal amplitude in our circadian assays. Thus, amplitude could simply be higher if there were more copies of the Per2 or Bmall gene inserted into the genome. However, basal period and drug-induced period and amplitude changes are independent of the integration factor and were therefore our primary parameters.

The clinical features of the patients did not readily explain the period variability observed within our BD cohort. Whilst our control cohort had a balanced sex distribution (F:M, 55:45), the BD cohort had a female bias (F: M, 74:26). Furthermore, the control cohort was on average 10 years older (BD 43 years vs. control 53 years). However, given there was no correlation between age and sex with basal circadian period or lithium response (Fig. S1) these factors are unlikely to account for our observed differences. Further, to take account of the variable sample numbers between the control and BD cohort, we used Welch's $t$ test which is better suited to handle variable sample sizes and variances [46, 47]. Disease diagnosis showed that BP-II patients had a shorter period than BP-I patients (by $1.1 \mathrm{~h}$, 
A repeated i.p. injections open field test (11-12 days)
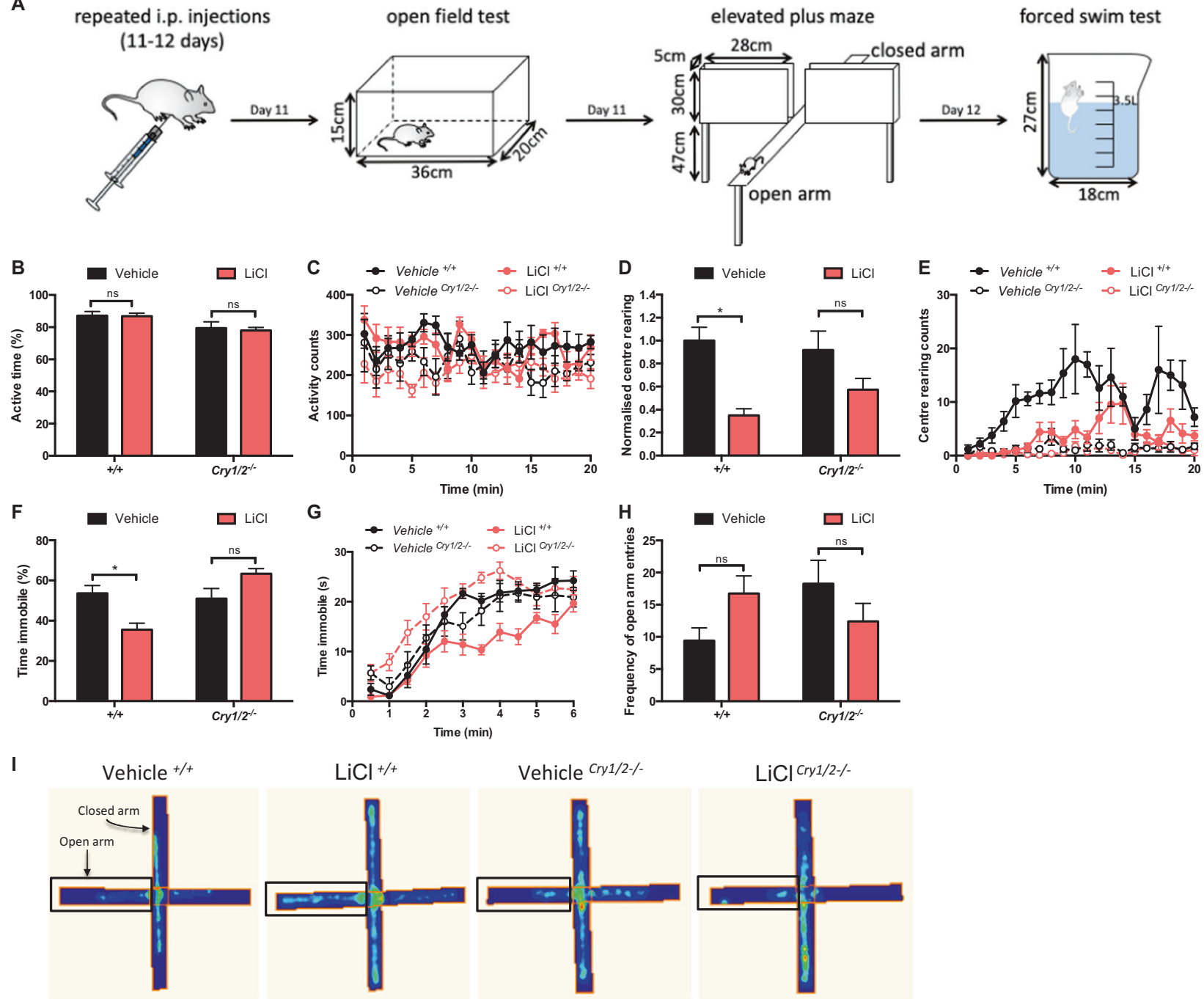

Fig. 5 Lithium treatment differentially modulates behavior in Cry1/ $2^{-/-}$mice. a Wild-type and Cryl/2 ${ }^{-/-}$mice were administered (i.p.) vehicle or $\mathrm{LiCl}$ (vehicle ${ }^{+/+}: n=6, \mathrm{LiCl}^{+/+}: n=7$, vehicle ${ }^{C r y l / 2-/-}: n=$ $\left.8, \mathrm{LiCl}^{\mathrm{Cryl} / 2-/-}: n=8\right)$ and tested by OFT, EPM, and FST. OFT effects of lithium on (b), (d) time spent active and the normalized number of center rears, with $(\mathbf{c}),(\mathbf{e})$ representative traces to visualize the treatment

$p=0.054)$. Although there are no reports directly comparing cellular rhythmicity in BP-I vs. BP-II patients, differences in sleep have been identified, and sleep efficiency and duration were improved only in BP-I patients taking lithium [48]. However, due to the limited sample size, it would be prudent to replicate this study with a larger cohort; if the observation is validated, this could enable the identification of appropriate chronomodulatory compounds in the future.

Our investigation confirms previous findings that lithium induces period lengthening and increases amplitude $[28,34,49,50]$. Further, we report that patient cells with longer circadian periods show reduced circadian responses to lithium. We also demonstrate that this deficit applies to other chronomodulatory compounds: CGS, NOB, and BIO and genotype differences in response to lithium. FST effects on (f), (g) time spent immobile. h EPM number of entries into the open arm. i Heat maps from representative mice highlighting behavioral differences in the EPM. Data were analyzed using a two-way ANOVA with a Sidak's post hoc test and presented as mean \pm s.e.m. ${ }^{*} p<0.05$.

(both period increasing and decreasing modulators). As CGS, NOB, and lithium function via distinct primary targets and cellular mechanisms (CGS: nonspecific adenosine antagonist [42]; NOB: multiple targets, including retinoid orphan receptor [41] and CREB [51]; lithium: multiple targets e.g., IMPase, GSK3 $\beta$ [52]), such altered chronomodulatory effects in patient fibroblasts in response to these drugs are unlikely to be mediated by changes in activity associated with a single target. Rather, our observations point to a general mechanistic aberration in these patients' clocks and the chronomodulatory agents driving the clock to an altered equilibrium to overcome these functional deficits. Indeed, the specific observation that lithium exerts differential circadian effects is supported by a 
recent study [53]. It is unlikely that the longer phenotype is a consequence of long-term medication, as the cells were passaged at least 4-6 times since biopsy, during which time the drugs would have washed out, excluding potential epigenetic changes. Further, there was no difference in circadian responses between Li-T and untreated cells. Whilst we cannot conclude that control-subject derived fibroblasts would not also show similar effects, such subjects would never need to take lithium therapeutically. Therefore, our primary focus was on understanding the lithium response across BD patients. Overall, we show that drug responses vary in BD patients based on the underlying cellular circadian rhythms. Thus, currently unidentified factors that are implicated in the functioning of the molecular clock may be significantly disrupted in patients with longer basal circadian periods. If this can be validated on a larger scale, with mood regulation as an additional outcome, patient-derived fibroblasts could become a meaningful biomarker and facilitate the implementation of a personalized approach to lithium treatment. Whilst lithium's established effects require long-term therapy to become apparent, we show almost immediate changes to circadian rhythms in our cell model. It has been shown with several other mood modulators that even in the absence of measurable changes in subjective mood, changes in emotional processing and memory are apparent after a single treatment [54]. This suggests that whilst the neurophysiological and mechanistic changes induced by these therapeutics are almost immediate, their translation into improved symptoms exhibit a lag [55]. Similarly to these agents, we hypothesize that beneficial alterations to circadian rhythms will initiate neurophysiological changes and promote improvements in patient symptoms.

Although screening for novel clock modulators has been performed on immortalized cells [56-58], as we do not fully understand $\mathrm{BD}$, use of our patient-derived fibroblasts have several advantages over existing models. Fibroblasts provide a more biologically relevant representation of the individual's genetic makeup, and they represent a valid indication of human physiological circadian rhythmicity (Table 1). This therefore provides researchers with a more accurate model of the disease, which may help identify patient-relevant pharmacological treatments in the future. Furthermore, the patients from whom our fibroblasts originated were extensively evaluated: each cell-line was accompanied by a wealth of long-term phenotypic information. Therefore, all these 39 fibroblast lines could be utilized in the future, or particular cell lines could be selected based on the research needs or the genetics behind the differential drug responses be explored. The creation of a patient-derived fibroblast model also significantly reduces the need for animals, including transgenic mice to model circadian rhythm deficits in mood disorders; replacing with a human relevant model will be highly beneficial at various stages of drug discovery, including high-throughput screening.

This investigation also found that the novel chronomodulatory drugs NOB and CGS reduce rearing and anxiety-related behavior, similar to lithium. This supports the theory that drugs that modulate circadian rhythm can alter temperament. Indeed, several lines of study support this; key examples include the fact that the melatonergic agonist agomelatine and light therapy normalize extreme behavioral irregularities such as depression, mania, and delusions [59-62]. Furthermore, work in Clock 19 mice has shown that lithium-induced behavioral responses are altered in a range of behavioral tests including EPM, OFT, and FST, thus yielding evidence for interactions between lithium, the molecular clock, and behavior. To provide further evidence that these effects are not specific to the Clock $\Delta 19$ genotype, we performed comparable behavioral experiments and showed that lithium's effects are indeed altered in Cryl/2 $2^{-/-}$mice, compared with controls. Collectively, these investigations provide evidence for the involvement of the molecular clock in lithium's behavioral effects.

In conclusion, patient-derived fibroblasts enabled the identification of differential drug responses based on basal circadian rhythms. This advances our understanding of the role of circadian rhythms in BD and supports the wealth of evidence demonstrating a close relationship between circadian rhythms and the pathophysiology of BD. If pharmacological modulation of circadian rhythms can provide a novel method to achieve mood stability, it will be necessary to validate these findings with additional molecules and in larger studies in the hope of identifying a new treatment paradigm for $\mathrm{BD}$ and perhaps other neuropsychiatric disorders.

Acknowledgements The work in SV lab was supported by the NC3Rs (NC/L001179/1) and BBSRC (BB/N001664/1). HS was supported by a studentship from the NC3Rs. Work in AJ lab was supported by the BBSRC (BB/N01992X/1), and RF lab was supported by the Wellcome Trust (WT106174/Z/14/ZMA). The work in SC Lab toward generating the fibroblast lines was supported by the Innovative Medicines Initiative Joint Undertaking (grant \#115439), composed of a financial contribution from the European Union's Seventh Framework Program (FP7/2007e2013) and an EFPIA Companies' In-Kind contribution. PH and ZC research was supported by the Oxford Health National Institute for Health Research (NIHR) Biomedical Research Center. The views expressed are those of the authors and not necessarily those of the National Health Service, NIHR or the Department of Health. We are grateful to Jithan Benjamin, Helen Jones, and the staff of the Oxford Cognitive Clinical Health Facility for their contributions in obtaining the patient samples. The authors would like to thank Dr. Michael Field and Trevor Sharp for their valuable advice on this manuscript. 


\section{Compliance with ethical standards}

Conflict of interest The authors declare that they have no conflict of interest.

Publisher's note Springer Nature remains neutral with regard to jurisdictional claims in published maps and institutional affiliations.

Open Access This article is licensed under a Creative Commons Attribution 4.0 International License, which permits use, sharing, adaptation, distribution and reproduction in any medium or format, as long as you give appropriate credit to the original author(s) and the source, provide a link to the Creative Commons license, and indicate if changes were made. The images or other third party material in this article are included in the article's Creative Commons license, unless indicated otherwise in a credit line to the material. If material is not included in the article's Creative Commons license and your intended use is not permitted by statutory regulation or exceeds the permitted use, you will need to obtain permission directly from the copyright holder. To view a copy of this license, visit http://creativecommons. org/licenses/by/4.0/.

\section{References}

1. Merikangas KR, Jin R, He JP, Kessler RC, Lee S, Sampson NA, et al. Prevalence and correlates of bipolar spectrum disorder in the World Mental Health Survey initiative. Arch Gen Psychiatry. 2011;68:241-51.

2. World Health Organization. The global burden of disease: 2004 update. Part 3 disease incidence, prevalence and disability. World Health Organization; 2008. https://www.who.int/healthinfo/global_ burden_disease/2004_report_update/en/.

3. Geddes JR, Burgess S, Hawton K, Jamison K, Goodwin GM. Long-term lithium therapy for bipolar disorder: systematic review and meta-analysis of randomized controlled trialls. Am J Psychiatry. 2004;161:217-22.

4. Geddes JR, Goodwin GM, Rendell J, Azorin JM, Cipriani A, Ostacher MJ, et al. Lithium plus valproate combination therapy versus monotherapy for relapse prevention in bipolar I disorder (BALANCE): a randomised open-label trial. Lancet. 2010;375:385-95.

5. Severus E, Taylor MJ, Sauer C, Pfennig A, Ritter P, Bauer M, et al. Lithium for prevention of mood episodes in bipolar disorders: systematic review and meta-analysis. Int J Bipolar Disord. 2014:2:15.

6. Gould TD, Quiroz JA, Singh J, Zarate CA, Manji HK. Emerging experimental therapeutics for bipolar disorder: insights from the molecular and cellular actions of current mood stabilizers. Mol Psychiatry. 2004;9:734-55.

7. Jagannath A, Peirson SN, Foster RG. Sleep and circadian rhythm disruption in neuropsychiatric illness. Curr Opin Neurobiol. 2013;23:888-94.

8. Wulff K, Gatti S, Wettstein JG, Foster RG. Sleep and circadian rhythm disruption in psychiatric and neurodegenerative disease perspectives. Nat Rev Neurosci. 2010;11:589.

9. Carr O, Saunders KEA, Bilderbeck AC, Tsanas A, Palmius N, Geddes JR, et al. Desynchronization of diurnal rhythms in bipolar disorder and borderline personality disorder. Transl Psychiatry. 2018;8:79.

10. Takahashi JS. Transcriptional architecture of the mammalian circadian clock. Nat Rev Genet. 2017;18:164-79.

11. Wulff K, Dijk DJ, Middleton B, Foster RG, Joyce EM. Sleep and circadian rhythm disruption in schizophrenia. Br J Psychiatry. 2012;200:308-16.
12. Germain A, Kupfer DJ. Circadian rhythm disturbances in depression. Hum Psychopharmacol. 2008;23:571-85.

13. McClung CA. How might circadian rhythms control mood? Let me count the ways. Biol Psychiatry. 2013;74:242-9.

14. American Psychiatric Association. Diagnostics and Statisitcal Manual of Mental Disorders (DSM). 5th ed. Washington: American Psychiatric Association; 2013.

15. Mansour HA, Wood J, Logue T, Chowdari KV, Dayal M, Kupfer DJ, et al. Association study of eight circadian genes with bipolar I disorder, schizoaffective disorder and schizophrenia. Genes Brain Behav. 2006;5:150-7.

16. Serretti A, Benedetti F, Mandelli L, Lorenzi C, Pirovano A, Colombo C, et al. Genetic dissection of psychopathological symptoms: Insomnia in mood disorders and CLOCK gene polymorphism. Am J Med Genet B Neuropsychiatr Genet. 2003; 121B:35-8

17. Roybal K, Theobold D, Graham A, DiNieri JA, Russo SJ, Krishnan V, et al. Mania-like behavior induced by disruption of CLOCK. Proc Natl Acad Sci USA. 2007;104:6406-11.

18. Kristensen M, Nierenberg AA, Ostergaard SD. Face and predictive validity of the Clock Delta 19 mouse as an animal model for bipolar disorder: a systematic review. Mol Psychiatry. 2018; 23:70-80.

19. Keers R, Pedroso I, Breen G, Aitchison KJ, Nolan PM, Cichon S, et al. Reduced anxiety and depression-like behaviours in the circadian period mutant mouse afterhours. PLoS ONE. 2012;7: e38263.

20. Godinho SIH, Maywood ES, Shaw L, Tucci V, Barnard AR, Busino L, et al. The after-hours mutant reveals a role for Fbxl3 in determining mammalian circadian period. Science. 2007;316: 897-900.

21. Siepka SM, Yoo SH, Park J, Song WM, Kumar V, Hu YN, et al. Circadian mutant overtime reveals F-box protein FBXL3 regulation of cryptochrome and period gene expression. Cell. 2007;129:1011-23.

22. Nagoshi E, Saini C, Bauer C, Laroche T, Naef F, Schibler U. Circadian gene expression in individual fibroblasts: Cellautonomous and self-sustained oscillators pass time to daughter cells. Cell. 2004;119:693-705.

23. Brown SA, Fleury-Olela F, Nagoshi E, Hauser C, Juge C, Meier $\mathrm{CA}$, et al. The period length of fibroblast circadian gene expression varies widely among human individuals. Plos Biol. 2005;3:1813-8.

24. Pagani L, Semenova EA, Moriggi E, Revell VL, Hack LM, Lockley SW, et al. The physiological period length of the human circadian clock in vivo is directly proportional to period in human fibroblasts. PLoS ONE. 2010;5:e13376.

25. Brown SA, Kunz D, Dumas A, Westermark PO, Vanselow K, Tilmann-Wahnschaffe A, et al. Molecular insights into human daily behavior. Proc Natl Acad Sci USA. 2008;105:1602-7.

26. McCarthy MJ, Wei H, Marnoy Z, Darvish RM, McPhie DL, Cohen BM, et al. Genetic and clinical factors predict lithium's effects on PER2 gene expression rhythms in cells from bipolar disorder patients. Transl Psychiatry. 2013;3:e318.

27. Bamne MN, Ponder CA, Wood JA, Mansour H, Frank E, Kupfer DJ, et al. Application of an ex vivo cellular model of circadian variation for bipolar disorder research: a proof of concept study. Bipolar Disord. 2013;15:694-700.

28. Osland TM, Ferno J, Havik B, Heuch I, Ruoff P, Laerum OD, et al. Lithium differentially affects clock gene expression in serum-shocked NIH-3T3 cells. J Psychopharmacol. 2011;25: 924-33.

29. Griggs CA, Malm SW, Jaime-Frias R, Smith CL. Valproic acid disrupts the oscillatory expression of core circadian rhythm transcription factors. Toxicol Appl Pharmacol. 2018;339:110-20. 
30. Hagihara H, Horikawa T, Nakamura HK, Umemori J, Shoji H, Kamitani Y, et al. Circadian gene circuitry predicts hyperactive behavior in a mood disorder mouse model. Cell Rep. 2016;14: 2784-96.

31. Engelmann W. Lithium slows down kalanchoe clock. Z Naturforsch B. 1972;B 27:477.

32. Klemfuss H. Rhythms and the pharmacology of lithium. Pharmacol Ther. 1992;56:53-78.

33. Johnsson A, Pflug B, Engelmann W, Klemke W. Effect of lithium-carbonate on circadian periodicity in humans. Pharmakopsychiatr Neuro-Psychopharmakologie. 1979;12:423-5.

34. Li J, Lu W-Q, Beesley S, Loudon ASI, Meng Q-J. Lithium impacts on the amplitude and period of the molecular circadian clockwork. PLoS ONE. 2012;7:e33292.

35. Geoffroy PA, Curis E, Courtin C, Moreira J, Morvillers T, Etain $\mathrm{B}$, et al. Lithium response in bipolar disorders and core clock genes expression. World J Biol Psychiatry. 2018;19:619-32.

36. Morrison M, Klein C, Clemann N, Collier D, Hardy J, Heisserer B, et al. StemBANCC: governing access to material and data in a large stem cell research consortium. Stem Cell Rev. 2015;11: 681-7.

37. Gossan N, Zeef L, Hensman J, Hughes A, Bateman JF, Rowley L, et al. The circadian clock in murine chondrocytes regulates genes controlling key aspects of cartilage homeostasis. Arthritis Rheum. 2013;65:2334-45.

38. Marino MP, Panigaj M, Ou W, Manirarora J, Wei CH, Reiser J. A scalable method to concentrate lentiviral vectors pseudotyped with measles virus glycoproteins. Gene Ther. 2015;22:280-5.

39. van der Horst GTJ, Muijtjens M, Kobayashi K, Takano R, Kanno S, Takao M, et al. Mammalian Cry1 and Cry2 are essential for maintenance of circadian rhythms. Nature. 1999;398:627-30.

40. Can A, Blackwell RA, Piantadosi SC, Dao DT, O'Donnell KC, Gould TD. Antidepressant-like responses to lithium in genetically diverse mouse strains. Genes Brain Behav. 2011;10:434-43.

41. He BK, Nohara K, Park N, Park YS, Guillory B, Zhao ZY, et al. The small molecule nobiletin targets the molecular oscillator to enhance circadian rhythms and protect against metabolic syndrome. Cell Metab. 2016;23:610-21.

42. Ongini E, Dionisotti S, Gessi S, Irenius E, Fredholm BB. Comparison of CGS15943, ZM241385 and SCH58261 as antagonists at human adenosine receptors. Naunyn Schmiedebergs Arch Pharmacol. 1999;359:7-10.

43. O'Donnell KC, Gould TD. The behavioral actions of lithium in rodent models: Leads to develop novel therapeutics. Neurosci Biobehav Rev. 2007;31:932-62.

44. Vitaterna MH, Selby CP, Todo T, Niwa H, Thompson C, Fruechte $\mathrm{EM}$, et al. Differential regulation of mammalian period genes and circadian rhythmicity by cryptochromes 1 and 2. Proc Natl Acad Sci USA. 1999;96:12114-9.

45. Yang S, Van Dongen HPA, Wang K, Berrettini W, Bucan M. Assessment of circadian function in fibroblasts of patients with bipolar disorder. Mol Psychiatry. 2009;14:143-55.

46. Ruxton GD. The unequal variance t-test is an underused alternative to Student's t-test and the Mann-Whitney U test. Behav Ecol. 2006;17:688-90.
47. Delacre M, Lakens D, Leys C. Why psychologists should by default Use Welch's t-test instead of student's t-test. Int Rev Soc Psychol. 2017;30:92-101.

48. Geoffroy PA, Samalin L, Llorca PM, Curis E, Bellivier F. Influence of lithium on sleep and chronotypes in remitted patients with bipolar disorder. J Affect Disord. 2016;204:32-9.

49. Noguchi T, Lo K, Diemer T, Welsh DK. Lithium effects on circadian rhythms in fibroblasts and suprachiasmatic nucleus slices from Cry knockout mice. Neurosci Lett. 2016;619:49-53.

50. Yoshikawa T, Honma S. Lithium lengthens circadian period of cultured brain slices in area specific manner. Behav Brain Res. 2016;314:30-7.

51. Nagase H, Yamakuni T, Matsuzaki K, Maruyama Y, Kasahara J, Hinohara $\mathrm{Y}$, et al. Mechanism of neurotrophic action of nobiletin in PC12D cells. Biochemistry. 2005;44:13683-91.

52. Malhi GS, Outhred T. Therapeutic mechanisms of lithium in bipolar disorder: recent advances and current understanding. CNS Drugs. 2016;30:931-49.

53. McCarthy MJ, Wei H, Nievergelt CM, Stautland A, Maihofer AX, Welsh DK, et al. Chronotype and cellular circadian rhythms predict the clinical response to lithium maintenance treatment in patients with bipolar disorder. Neuropsychopharmacology. 2019;44:620-8.

54. Harmer CJ, Shelley NC, Cowen PJ, Goodwin GM. Increased positive versus negative affective perception and memory in healthy volunteers following selective serotonin and norepinephrine reuptake inhibition. Am J Psychiatry. 2004;161: 1256-63.

55. Harmer CJ, O'Sullivan U, Favaron E, Massey-Chase R, Ayres R, Reinecke A, et al. Effect of acute antidepressant administration on negative affective bias in depressed patients. Am J Psychiatry. 2009; 166:1178-84.

56. Hirota T, Lewis WG, Liu AC, Lee JW, Schultz PG, Kay SA. A chemical biology approach reveals period shortening of the mammalian circadian clock by specific inhibition of GSK-3 beta. Proc Natl Acad Sci USA. 2008;105:20746-51.

57. Hirota T, Lee JW, Lewis WG, Zhang EE, Breton G, Liu X, et al. High-throughput chemical screen identifies a novel potent modulator of cellular circadian rhythms and reveals CKI alpha as a clock regulatory kinase. Plos Biol. 2010;8:e1000559.

58. Tamai TK, Nakane Y, Ota W, Kobayashi A, Ishiguro M, Kadofusa $\mathrm{N}$, et al. Identification of circadian clock modulators from existing drugs. EMBO Mol Med. 2018;10:e8724.

59. Olie JP, Kasper S. Efficacy of agomelatine, a MT1/MT2 receptor agonist with 5-HT2C antagonistic properties, in major depressive disorder. Int J Neuropsychopharmacol. 2007;10:661-73.

60. Rosenthal NE, Sack DA, Gillin JC, Lewy AJ, Goodwin FK, Davenport Y, et al. Seasonal affective-disorder-a description of the syndrome and preliminary findings with light therapy. Arch Gen Psychiatry. 1984;41:72-80.

61. Myers E, Startup H, Freeman D. Cognitive behavioural treatment of insomnia in individuals with persistent persecutory delusions: a pilot trial. J Behav Ther Exp Psychiatry. 2011;42:330-6.

62. Wirz-Justice A. Biological rhythm disturbances in mood disorders. Int Clin Psychopharmacol. 2006;21:S11-5. 